\title{
DESIGN VIDEO PROFILE BASED MULTIMEDIA AUDIO VISUAL AND BROADCASTING AS A MEDIA PROMOTION
}

\author{
Lusyani Sunarya $^{1}$ \\ Putri Apryllia ${ }^{2}$ \\ Siti Isnaini ${ }^{3}$ \\ Dosen STMIK Raharja Jurusan Teknik Informatika ${ }^{1}$, Alumni STMIK Raharja Jurusan Teknik \\ Informatika ${ }^{2}$, Alumni STMIK Raharja Jurusan Teknik Informatika ${ }^{3}$ \\ Email : lusyani@raharja.info, putri.apryllia@raharja.info, sitisnaini@ raharja.info
}

Diterima : 4 Juli 2016/Disetujui : 19 Juli 2016

\begin{abstract}
The development of media campaign currently very rapid. Media campaign that is widely used today not only in the form of visual communication media, but many companies that develop the promotion through audio-visual media. The development of the hospitality world increasingly rapidly, causing more and more facilities and advantages that should be promoted in order to compete, especially at Padjadjaran Suites Busines \& Conference Hotel. The aim of this study was to design-based audiovisual media in order to become an effective appeal, especially in the delivery of information and promotion of it - matters relating to the overall Padjadjaran Suites Busines \& Conference Hotel. Padjadjaran Suites Business \& Conference Hotel is a four star hotel located in Tangerang. Existing problems that the media used by Padjadjaran Suites Business \& Conference Hotel is in the form of visual communication media, in general, people are more receptive to information through interactive media and communicative, so Padjadjaran Suites Business \& Conference Hotel requires video media profile as a medium for supporting information and promotion at the show to prospective customers, establish relationships with clients, or as a medium of information to the public, so that the design of video media profile that show the entire scope, advantages and facilities of the hotel, could be a solution in solving problems in media promotion and information. The methods used in this research is a method of analysis of the problems, methods of data collection, data analysis, methods of analysis, as well as the basic concepts of media production. In the basic concepts of media production there are stages of preproduction, production, and postproduction. The end result of this design is a video that can be directly used for media promotion.
\end{abstract}

Keywords : Promotion, Audio Visual, Video Profile.

\begin{abstract}
ABSTRAKSI
Perkembangan media promosi saat ini sangatlah pesat. Media promosi yang banyak digunakan saat ini tidak hanya berbentuk media komunikasi visual, namun banyak perusahaan yang mengembangkan promosinya melalui media audio visual. Perkembangan dunia perhotelan yang makin pesat, menyebabkan semakin banyaknya fasilitas dan keunggulan yang harus di promosikan untuk bersaing, khususnya pada Padjadjaran Suites Busines \& Conference Hotel. Tujuan penelitian ini adalah merancang media berbasis audio visual agar dapat menjadi daya tarik yang efektif, terutama dalam penyampaian informasi dan promosi mengenai hal - hal yang berkaitan dengan keseluruhan isi Padjadjaran Suites Busines \& Conference Hotel. Padjajaran Suites Business \& Conference Hotel merupakan hotel bintang empat yang terletak di Tangerang. Permasalahan yang ada yaitu media yang digunakan oleh Padjajaran Suites Business \& Conference Hotel masih berupa media komunikasi visual, pada umumnya masyarakat lebih mudah menerima informasi melalui media yang interaktif dan komunikatif, sehingga Padjadjaran Suites Business \& Conference Hotel membutuhkan media video profile sebagai media penunjang informasi dan promosi yang di tunjukkan kepada calon customer, menjalin relasi dengan klien, ataupun sebagai media informasi kepada masyarakat, sehingga perancangan media video profile yang menampilkan seluruh ruang lingkup, keunggulan, dan fasilitas yang dimiliki hotel tersebut, dapat menjadi solusi dalam pemecahan masalah pada media promosi dan informasinya. Metode yang digunakan dalam penelitian ini adalah metode analisa
\end{abstract}


permasalahan, metode pengumpulan data, analisa data, metode analisa perancangan, serta konsep dasar produksi media. Di dalam konsep dasar produksi media terdapat tahap preproduction, production, dan postproduction. Hasil akhir dari perancangan ini adalah sebuah video yang bisa langsung digunakan untuk media promosi.

Kata kunci : Promosi, Audio Visual, Video Profile.

\section{PENDAHULUAN}

Saat ini banyak instansi atau perusahaan menggunakan media video sebagai sarana untuk menginformasikan dan mempromosikan perusahaannya. Video merupakan media yang paling lengkap, karena video mempunyai unsur gerak, visualisasi yang nyata, gambar, suara, dan juga banyak unsur musik dalam satu unit atau yang disebut juga dengan multimedia.

Promosi merupakan salah satu penentu keberhasilan suatu program pemasaran dalam suatu perusahaan.Pada hakikatnya promosi adalah suatu bentuk komunikasi pemasaran, yang dimaksud dengan komunikasi pemasaran adalah aktivitas pemasaran yang berusaha menyebarkan informasi, mempengaruhi atau membujuk, dan mengingatkan pasar sasaran atas perusahaan dan produknya, agar bersedia menerima dan loyal pada produk yang ditawarkan perusahaan yang bersangkutan.

Video profile adalah sebuah gambaran informasi tentang riwayat seseorang atau sebuah instansi perusahaan yang telah mencapai suatu pencapaian kesuksesan, dalam hal produksi atau hasil karya yang telah dihasilkan dan diterima di kalangan masyarakat umum.Informasi tersebut disebarkan berbentuk audio visual atau video.

Padjadjaran Suites Business \& Conference Hotel merupakan hotel bintang empat yang terletak di Jalan Pembangunan 3 No.17 - Tangerang, yang baru dibuka awal tahun 2014 lalu. Padjadjaran Suites Business \& Conference Hotel dilengkapi dengan features \& facilities 119 kamar yang terbagi dengan 4 tipe kamar, yakni Superior Room, Deluxe Room, Junior Suite and Royal Suite.

Media informasi dan promosi yang ada di Padjadjaran Suites Business \& Conference Hotel saat inimasih berupa media komunikasi visual, pada umumnya masyarakat, lebih mudah menerima informasi melalui media yang interaktif dan komunikatif, dan saat ini persaingan di dunia perhotelan juga berkembang semakin pesat, sehingga Padjadjaran Suites Business \& Conference Hotel membutuhkan video profile sebagai media penunjang informasi dan promosi yang di tunjukkan kepada calon customer, menjalin relasi dengan klien, ataupun sebagai media informasi kepada masyarakat, sehingga perancangan media video profile ini dapat menjadi solusi dalam pemecahan masalah pada media promosi dan informasinya.

Dari hasil analisa kebutuhan yang dilakukan terhadap Padjadjaran Suites Business \& Conference Hotel, perusahaan tersebut membutuhkan media informasi dan promosi yang menarik untuk memperkenalkan seluruh kapasitas perusahaan dan diharapkan melalui perancangan media video profile ini dapat meningkatkan omset perusahaan.

\section{RUMUSAN MASALAH}

Saat ini perkembangan media promosi berkembang sangat pesat.Media yang banyak digunakan saat ini dapat berupa media komunikasi visual maupun audio visual. Banyak perusahaan yang sudah menggunakan media audio visual sebagai salah satu cara untuk mempromosikan suatu instansi atau perusahaan. Media audio visual merupakan media yang paling mudah dipahami dan dimengerti oleh audience, karena di dalamnya terdapat unsur - unsur yang menarik, baik dari segi pengambilan gambar maupun editing.

Permasalahan yang melatar belakangi penelitian ini adalah kurangnya media promosi yang digunakan oleh Padjadjaran Suites Business \& Conference Hotel dalam mempromosikan secara keseluruhan apa yang ada dan disediakan oleh Padjadjaran Suites Business \& Conference Hotel, karena dalam melaksanakan suatu promosi masih menggunakan sebuah media promosi berupa media cetak, maka dari itu dibuatlah suatu 
teknik promosi baru untuk Padjadjaran Suites Business \& Conference Hotel dengan menggunakan video profile.

\section{LANDASAN TEORI}

\section{Konsep Dasar Video Profile}

Video profile adalah sebuah gambaran informasi tentang riwayat seseorang atau sebuah instansi perusahaan yang telah mencapai suatu pencapaian kesuksesan dalam hal produksi atau hasil karya yang telah dihasilkan dan diterima di kalangan masyarakat umum. Informasi tersebut disebarkan berbentuk audio visual atau video.[5]

Video profile perusahaan (corporate profile) merupakan video yang diproduksi untuk keperluan tertentu, misalnya memperkenalkan suatu perusahaan tertentu untuk disebar luaskan ke publik, selain itu sering dipakai sebagai sarana pendukung dalam suatu presentasi perusahaan atau kelompok tertentu.[9]

Dilihat dari penjelasan diatas maka dapat disimpulkan video profile adalah sebuah tampilan audio visual yang digunakan untuk memperkenalkan dan menginformasikan tentang segala sesuatu penjelasan dan keunggulan yang telah dimiliki sebuah instasi, perusahaan, atau perorangan untuk disebarkan kepada masyarakat dalam bentuk video.

\section{Konsep Dasar Promosi}

Promosi adalah suatu bentuk komunikasi pemasaran. Yang dimaksud dengan komunikasi pemasaran adalah aktivitas pemasaran yang berusaha menyebarkan informasi, mempengaruhi atau membujuk, dan mengingatkan pasar sasaran atas perusahaan dan produknya agar bersedia menerima dan loyal pada produk yang ditawarkan perusahaan yang bersangkutan.[6]

Promosi merupakan salah satu penentu keberhasilan suatu program pemasaran.Pentingnya promosi dapat digambarkan lewat perumpamaan bahwa pemasaran tanpa promosi dapat diibaratkan seorang pria berkaca mata hitam yang dari tempat gelap pada malam kelam mengedipkan matanya pada seorang gadis di kejauhan. Tak seorang pun yang tau apa yang dilakukan pria tersebut selain dirinya sendiri.

\section{Konsep Dasar Multimedia Audio Visual and Broadcasting}

\section{Pengertian Multimedia}

Multimedia adalah kombinasi dari komputer dan video (Rosch, 1996) atau multimedia secara umum merupakan penggabungan tiga elemen yaitu suara, gambar dan teks (Mc Cormiks, 1996).[7]

Multimedia adalah penggunaan komputer untuk menampilkan teks, grafik, video, animasi dan suara dalam bentuk terpadu.Multimedia adalah gabungan antara visual, audio, grafik dan teks dalam suatu produksi bertingkat berbasis komputer yang dapat dialami secara interaktif.[3]

\section{Pengertian Audio Visual}

Audio visual merupakan gabungan dari dua kata yang berarti suara dan visual yang berarti gambar, atau dengan kata lain menjelaskan audio visual adalah alat peraga yang dapat dilihat dan didengar dalam hal ini gambar bergerak menimbulkan suara.[2]

\section{Pengertian Broadcasting}

Broadcasting adalah distribusi audio visual atau video yang mengirimkan sinyal program untuk penonton.Para penonton mungkin masyarakat umum yang relatif besar sub-penonton, seperti anak-anak atau orang dewasa muda.Broadcasting sudah tidak asing lagi di kalangan masyarakat. Penyebaran informasi berfokus pada pesan dan diteruskan dari satu sumber utama untuk salah satu penonton yang besar tanpa pertukaran dialog di antara keduanya. Sebenarnya tidak ada cara untuk menetapkan sebelumnya bagaimana penduduk atau audiens yang lebih besar akan menyerap pesan. Mereka dapat memilih untuk mendengarkan, menganalisis, atau hanya mengabaikannya. Penyebarluasan dalam komunikasi secara luas digunakan dalam dunia penyiaran.[1] 


\section{Pengertian Storyboard}

Storyboard adalah rangkaian gambar ilustrasi yang berusaha menjelaskan bahasa tulisan scenario kedalam bahasa visual.[8]

Storyboard adalah rancangan berupa sket gambar yang dilengkapi dengan petunjuk atau catatan pengambilan gambar untuk kebutuhan shooting. Selama proses praproduksi, perancangan yang berhubungan dengan visualisasi yang akan dibuat membutuhkan storyboard sebagai media terpadu.[4]

Dilihat dari penjelasan diatas maka dapat disimpulkan multimedia audio visual and broadcasting adalah penggabungan 3elemen dari unsur-unsur penyampaian ide imajinasi menjadi satu kesatuan untuk menghasilkan sebuah keluaran berupa tampilan gambar dan suara yang menarik.

\section{LITERATURE REVIEW}

1. Multimedia Sebagai Pembuatan Company Profile Pada Sekolah Menengah Seni Rupa Yogyakarta adalah salah satu judul Tugas Akhir yang dibuat oleh Riki Novtrian, Ratih Oktavani, dan Fiktori Agus Saputro selaku mahasiswa STMIK AMIKOM Yogyakarta. Penelitian ini menjelaskan tentang sekolah yang mengalami kesulitan dalam mempublikasikan sekolahnya, maka dibuatlah solusi yaitu sebuah company profile yang berbentuk CD kepada Sekolah Menengah Seni Rupa (SMSR) agar pempublikasian tepat sasaran dan memberikan informasi berbagai macam program keahlian yang ditawarkan SMSR Yogyakarta kepada calon siswa. Kelebihan dari penelitian ini adalah terdapat sentuhan animasi 2D yang mejadikan video menjadi lebih menarik, sedangkan kekurangannya adalah media penyampaian promosi yang digunakan masih menggunakan compact disk (CD).

2. Pembuatan Video Company Profile Berbasis Multimedia Pada Sekolah Menengah Pertama Negeri 4 Karanganyar adalah salah satu judul jurnal yang dibuat oleh Sesar Wahyu E.P selaku mahasiswa Universitas Surakarta. Penelitian ini menjelaskan tentang kurangnya sarana atau media publikasi yang dimiliki oleh SMP Negeri 4 Karanganyar, dan tujuan dari penelitian ini adalah untuk menghasilkan video company profile yang akan digunakan oleh SMP Negeri 4 Karanganyar sebagai media untuk promosi. Kelebihan dari video profile ini promosi yang digunakan menggunakan media DVD, sedangkan kekurangannya adalah kurangnya penjelsan mengenai aplikasi apa sajayang digunakan untuk mengedit video agar lebih menarik.

3. Analisis dan Perancangan Video Iklan Pada Hotel Duta Garden Yogyakarta sebagai Media Promosi adalah jurnal yang dibuat oleh Yanu Rahinda yang merupakan mahasiswa STMIK AMIKOM Yogyakarta. Penelitian ini menjelaskan tentang perancangan media video iklan sebagai media promosi untuk meningkatkan angka pengunjung serta mengangkat citra baik Hotel Duta Garden Yogyakarta.Kelebihan yang ada pada penelitian ini yaitu terletak pada penjelasan mengenai media iklan serta tahapan yang harus dilakukan pada saat pembuatan iklan, sedangkan kekurangan yang ada pada penelitian ini adalah tidak adanya tampilan video yang dbuat untuk Hotel Duta GardenYogyakarta.

4. Media Company Profile Sebagai Sarana Penunjang Informasi dan Promosi adalah sebuah jurnal yang dibuat oleh Maimunah, Lusyani Sunarya, dan Nina Larasti yang merupakan Dosen serta mahasiswa STMIK Raharja. Penelitian ini membahas tentang kurangnya media promosi yang digunakan oleh PT Inovasi Multi Teknologi, sehingga dibuatlah Media Company Profile sebagai salah satu media penunjang informasi dan promosi yang akan digunakan oleh PT Inovasi Multi Teknologi. Kelebihan yang ada pada company profile ini adalah penjelasan mengenai pembuatannya sangat jelas, sedangkan kekurangannya adalah belum menggunakan tampilan 2D maupun 3D.

5. Penelitian yang dilakukan oleh Anita B. Wandanaya, Dewi Immaniar, dan Maryana Astuti dengan judul Design Visualisasi Logo Sebagai Identity Programs Di Divisi Raharja Enrichment 
Centre membahas tentang bagaimana membuat sebuah rancangan Identitas Logo yang menarik dan mewakili citra atau image Raharja Enrichment Centre (REC) sehingga menghasilkam sebuah tampilan logo yang menarik, warna yang harmonis dan font yang kreatif serta bagaimana Identitas Logo ini di implementasikan sebagai identitas visual dalam menampilkan programprogram Raharja Enrichment Centre (REC) dan dapat memberikan karakteristik khusus pada setiap program-program Raharja Enrichment Centre tersebut agar terlihat berbeda pada setiap programnya. Kelebihan daripada penelitian ini adalah hasil dari desain yang dibuat sangat bagus, sedangkan kekurangannya tampilan yang dihasilkan masih sedikit kurang menarik.

\section{METODE PENELITIAN}

Agar perolehan data lebih akurat dipenelitian ini, terdapat beberapa penerapan metode, yaitu : (1). Metode Analisa Permasalahan. Metode ini merupakan suatu metode yang digunakan untuk menentukan topik permasalahan penelitian, dalam hal ini dilakukan dengan bentuk interview yang menanyakan tentang permasalahan - permasalahan yang terdapat pada lembaga instansi yang terkait dengan proses mempromosikan sebuah hotel; (2). Metode Pengumpulan Data yaitu cara untuk mendapatkan data dengan jalan pengamatan secara langsung ke lokasi (Observasi), Interview ataupun dari kajian pustaka; (3).Analisa Data berupa pengolahan data atau informasi yang diangkat dari hasil perancangan dan penelitian terhadap profile Padjadjaran Suites Business \& Conference Hotel yang akan dianalisa dan diolah menggunakan software atau aplikasi program yang mendukung dalam proses perancangan; (4).Metode Analisa Perancangan, dalam produksi Perancangan Video Profile Sebagai Media Promosi pada Padjadjaran Suites Business \& Conference Hotel dipergunakan aplikasi-aplikasi penunjang diantaranya aplikasi Adobe Premiere CS6 sebagai pengolah video setelah dilakukan produksi, sedangkan aplikasi Adobe After Effect CS6 dipergunakan untuk pembuatan animasi bumper saat opening maupun closing; (5). Konsep Dasar Media berisi mengenai Preproduction, Production, dan Postproduction.

\section{PEMBAHASAN}

Membuat suatu desain multimedia perlu melalui tahap-tahap perancangan agar mendapatkan suatu gambaran tentang produk yang akan dibuat. Sehingga mempermudah kita dalam pembuatan video profile.Tahapan yang dilakukan dalam melakukan konsep dasar media adalah Preproduction, Production, dan Postproduction.Untuk lebih jelas tentang tahap konsep produksi media bisa perhatikan gambar 1 yaitu skema konsep produksi media.

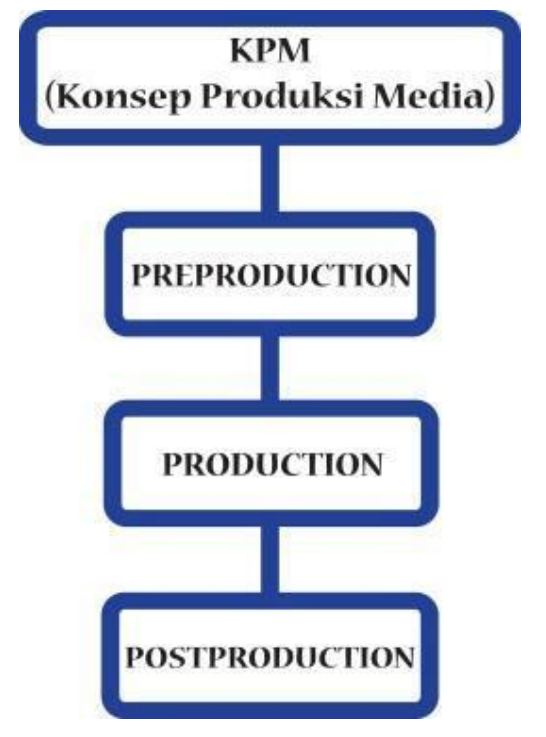

Gambar 1. Konsep Produksi Media

\section{PREPRODUCTION}

Untuk Preproduction adalah step atau langkah dimana dimulainya ide, perencanaan dan persiapan dari Konsep Produksi Media. Dilihat pada gambar 2 terdapat tujuh langkah Preproduction dalam Konsep Produksi Media, dimulai dari Ide yang dituangkan secara sistematis, lalu diikuti dengan pembuatan sinopsis, Script Writting dan Storyboard. 


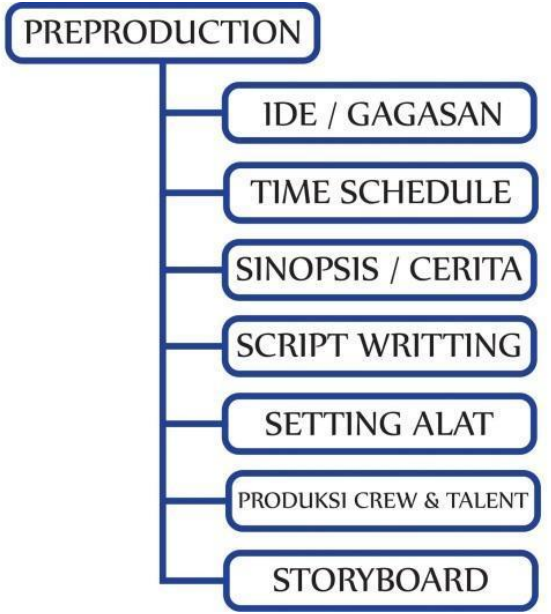

Gambar 2.Prepoduction

\section{Kerangka Pemikiran (Ide)}



\section{Gambar 3. Kerangka Pemikiran}

Kerangka pemikiran yang terdapat pada gambar 3 merupakan alur yang terdapat pada preproduction yaitu ide.Ide sangat dbutuhkan karena ide merupakan hal yang terpenting dalam tahap prepoduction.

\section{Sinopsis}

Sinopsis / cerita merupakan konsep cerita yang akan dibuat atau mencerminkan alur cerita dari awal sampai akhir adegan. Sinopsis perancangan video company profile sebagai media informasi dan promosi pada Padjadjaran Suites Business \& Conference Hotel ini adalah :

"Suasana pagi hari, tampak gedung Padjadjaran Suites Business \& Conference Hotel yang berdiri kokoh di Tangerang. Tak lama datang sebuah mobil Padjadjaran Suites membawa 2 tamu (pria \& wanita) yang akan menginap. Sesampainya mobil didepan pintu hotel, tamu dari dalam mobil dibukakan pintu mobil oleh supir, lalu tamu turun dari mobil.Saat tamu sudah memasuki area hotel, karyawan hotel (bell boy) menurunkan koper tamu dari dalam mobil. Tamu menuju ruang reservation untuk melakukan proses Check in. Dengan ramah karyawan reservation menyapa tamu yang akan melakukan booking room. Karyawan reservation mendata tamu \& memberikan kartu kamar kepada tamu. Selesai proses Check - in kemudian tamu menuju kamar dan diantar oleh karyawan hotel (bell boy) yang juga membawa koper tamu. Menampilkan Suasana Superior Room (Double Bed \& Twin Bed), menampilkan suasana koridor menuju Deluxe Room (Double Bed \& Twin Bed), Suasana Junior Suite, Suasana Royal Suite. Tak lama kemudian tamu (wanita) datang ke spa dan disambut oleh karyawan spa lalu diantar ke kamar untuk melakukan spa. Menampilkan suasana Executive Lounge dan Tamu (wanita \& pria) dari arah lift datang mепији Bale Bancakan Restaurant untuk makan siang, sesampainya di restaurant tamu disambut oleh karyawan restaurant (wanita) dengan ramah \& tersenyum. Dari arah bar seorang barista (wanita) sedang membuat minuman dan dalam dapur koki sedang memasak makanan yang dipesan oleh tamu.Tak lama kemudian karyawan restaurant datang dan megantarkan pesanan makanan \& minuman kepada tamu yang menunggu dimeja makan.Suasana sore hari kolam renang dan Hegarmanah Restaurant.Menampilkan suasana Ballroom untuk Wedding di Bale Pakuan dan Bridal Room di Junior Suites Room. Menampilkan suasana ruang meeting room di Rancage dan Bale Pakuan. Karyawan room boy (pria) 
sedang merapihkan dan membersihkan kamar tamu”.

\section{Story Board}

Tabel 1.Storyboard

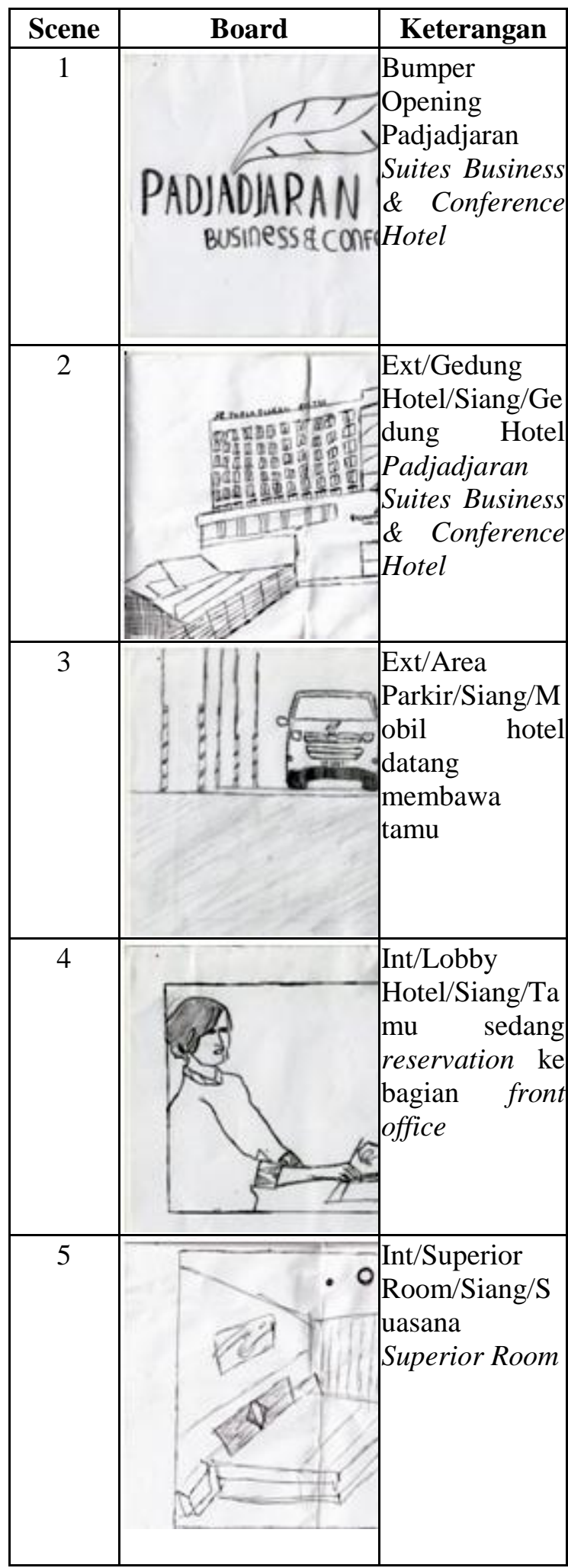

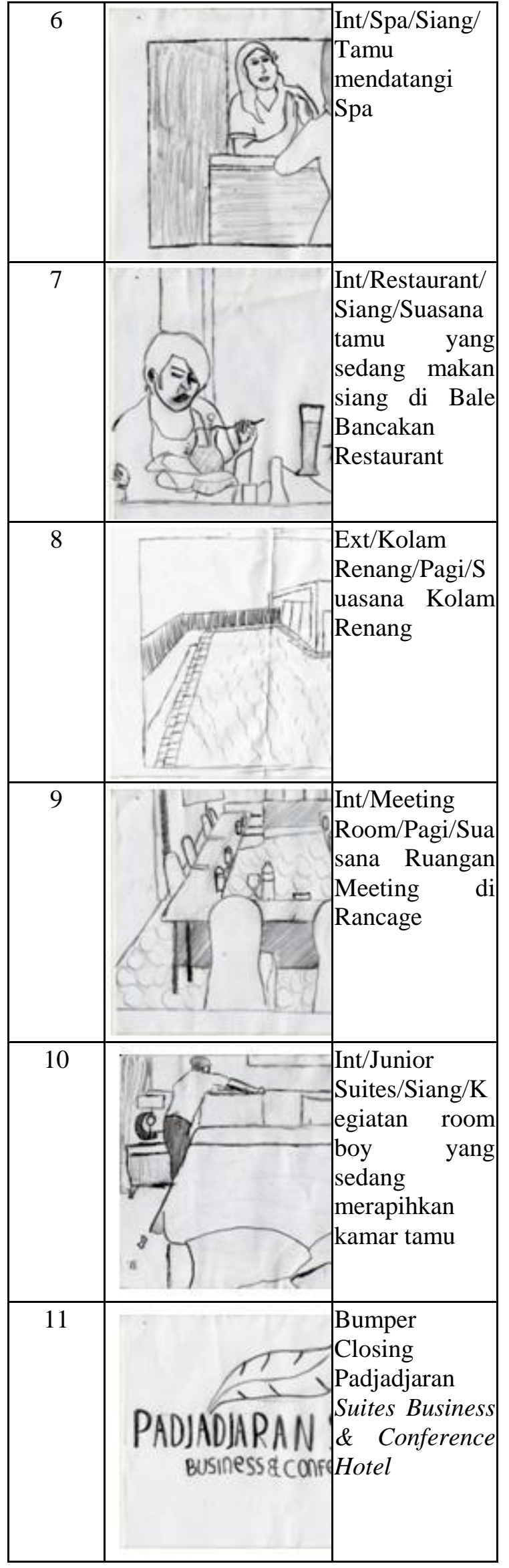




\section{PRODUCTION}

Production adalah proses pengambilan gambar atau shooting video dengan bekerjasamanya antara pemain dan crew untuk pewujudan rumusan dari tahap preproduction dalam bentuk skenario, naskah, dan storyboard yang telah dibuat.



\section{Gambar 4.Production}

Di dalam tahap production yang terdapat pada gambar 4 menjelaskan tentang hal - hal yang dilakukan pada tahap production.

\section{POSTPRODUCTION}

Postproduction adalah tahapan terakhir dari perancangan Konsep Produksi Media (KPM). Tahap postproduction adalah proses finishing sebuah karya sampai menjadi sebuah video yang utuh dan mampu menyampaikan sebuah cerita atau pesan kepada audience. Gambar 5 di bawah merupakan tahap akhir pada konsep produksi media yaitu postproduction.Terdapat enam tahap pada postproduction, yaitu digitizing, editing, mixing, dfinishing, exporting, dan segmen pasar.

\section{POSTPRODUCTION}

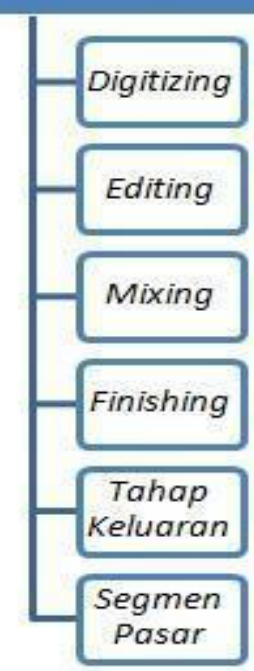

Gambar 5. Postproduction

\section{Tampilan Isi}

Tampilan isi mengambil dari profile Padjadjaran Suites Business \& Conference Hotel, yaitu meliputi keunggulan, fasilitasfasilitas, dan memaparkan segala sesuatu tentang Padjadjaran Suites Business \& Conference Hotel. Gambar 6 sampai gambar 16 memaparkan tentang tampilan isi video yang dihasilkan melalui proses perancangan konsep produksi media.

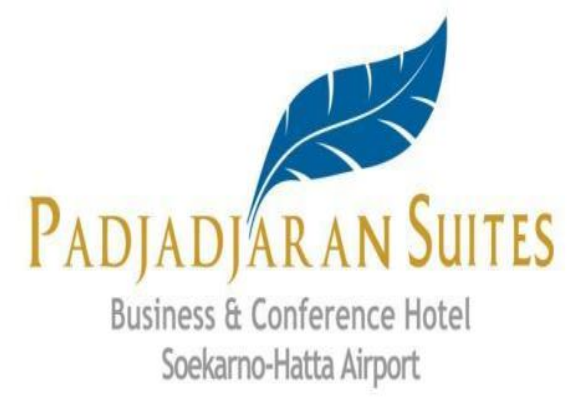

Gambar 6. Bumper Awal

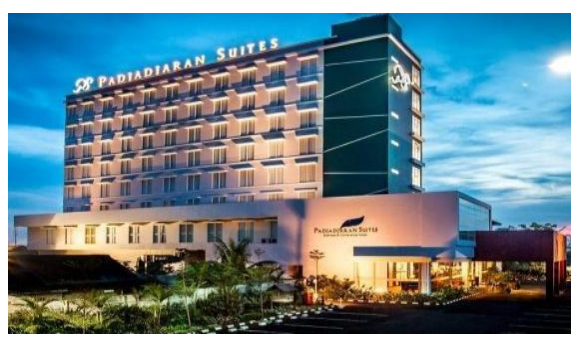

Gambar 7.Tampilan Gedung Padjadjaran Suites Business \& Conference Hotel. 


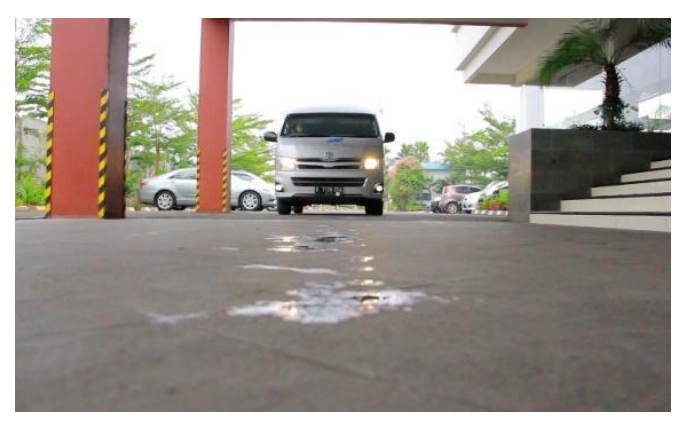

Gambar 8. Tampilan mobil hotel yang datang membawa tamu

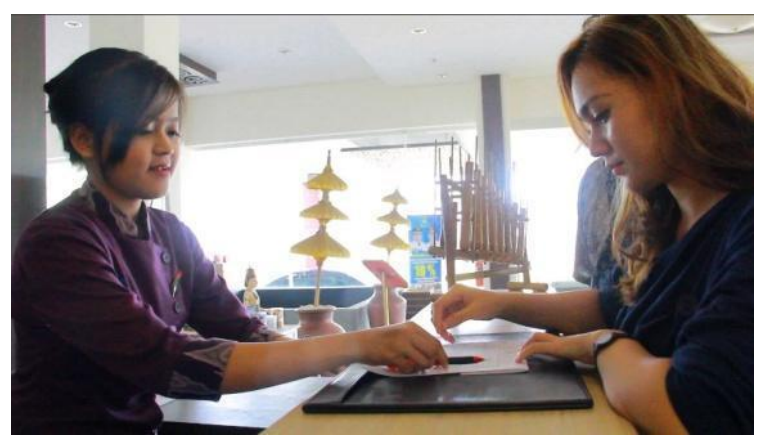

Gambar 9. Tamu sedang reservation ke bagian front office

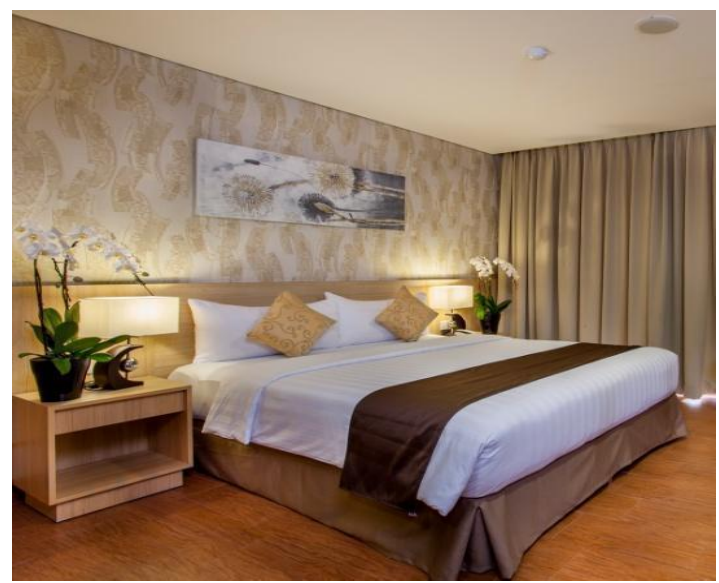

Gambar 10. Suasana Superior Room



Gambar 11. Tamu mendatangi Spa

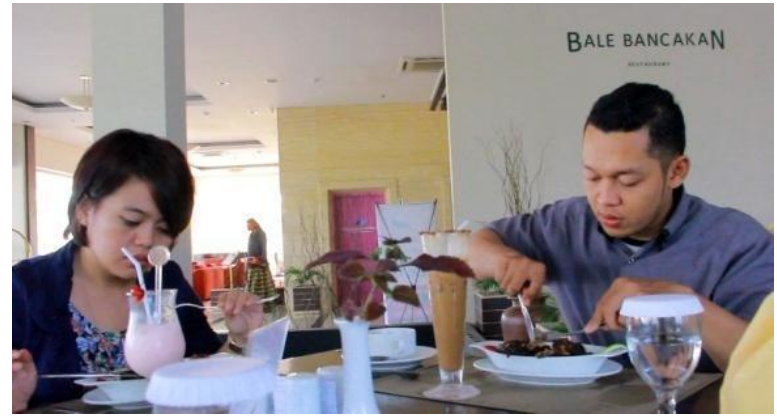

Gambar 12. Suasana tamu yang sedang makan siang di Bale Bancakan Restaurant



Gambar 13. Suasana Kolam Renang

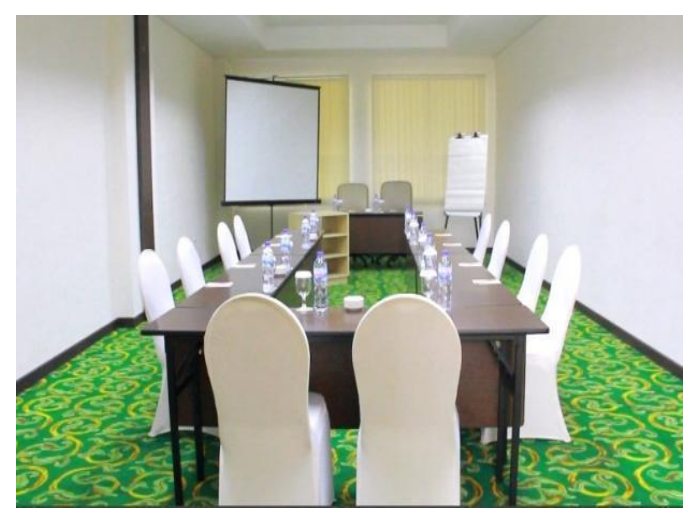

Gambar 14. Suasana Ruangan

Meeting di Rancage



Gambar 15. Kegiatan room boy yang sedang merapihkan kamar tamu 




Gambar 16. Bumper Closing

\section{KESIMPULAN}

Media yang tepat untuk menginformasikan dan mempromosikan Padjadjaran Suites Business \& Conference Hotel adalah dalam bentuk media video profile, karena media video profile menampilkan rangkaian audio visual berupa gambar, video, dan musik secara terangkai atau berurutan dengan konsep tertentu yang digunakan untuk keperluan seperti untuk memperkenalkan, menginformasikan, dan mempromosikan Padjadjaran Suites Business \& Conference Hotel kepada audience, cara merancang video profile yang menarik dan efektif dengan membuat sebuah video profile berisikan tentang keunggulan dan fasilitas yang dimiliki hotel tersebut dengan menyajikan informasi yang jelas dan up to date sesuai dengan perkembangan hotel saat ini. Agar tampilan lebih menarik diperlukan penyatuan effect visual, gambar, dan suara yang dikemas kedalam video profile dan video ini ditampilkan dalam durasi yang tidak terlalu panjang dan jelas, untuk lebih tepat sasaran dalam mempromosikan dan menginformasikan video profile ini sebaiknya disalurkan melalui DVD dan media sosial seperti Facebook, Youtube dan Website. Melalui perancangan video profile ini diharapkan Padjadjaran Suites Buisness \& Conference Hotel mencapai tingkatan target klien lebih besar dan lebih tepat sasaran, sehingga hotel tersebut dapat lebih dikenal oleh masyarakat luas.

\section{DAFTAR PUSTAKA}

[1] Arifin, Eva. 2010. Broadcasting To Be Broadcaster, Yogyakarta : Graha Ilmu
[2] Atmohoetomo, Soegito. 2010. Media Audio Visual Pendidikan dan Proses Produksi Programnya, Yogyakarta : Pusdiklat Perpustakaan IKIP.

[3] Binanto, Iwan. 2010. Multimedia Digital (Dasar Teori dan Pengembangannya), Yogyakarta : Andi.

[4] Desrianti, Dewi Immaniar. Untung Rahardja. Reni Mulyani. 2012. Audio Visual As One Of The Teaching Resources On iLearning. Journal CCIT Vol. 5 No. 2.

[5] Kuswandi, Wawan. 2010. Komunikasi Massa Sebuah Analisis Media Televisi, Jakarta : Rineka Cipta.

[6] Lukiati, Komala. 2010. Panduan Mudah Merancang Bangunan, Jakarta : Niaga Swadaya.

[7] Novtrian, Riki. Ratih Oktavani. Fiktori Agus Saputro. 2010 .Multimedia Sebagai

Pembuatan Company Profile Pada Sekolah Menengah Seni Rupa Yogyakarta. STMIK AMIKOM YOGYAKARTA.

[8] Maimunah. Lusyani Sunarya. Nina Larasati. 2012. Media Company Profile Sebagai

Sarana Penunjang Informasi dan Promosi. Journal CCIT Vol. 5 No. 3.

[9] Rahardja, Untung. Sugeng Widada. Dewi Immaniar Desrianti . 2010. KPM Sebagai Pedoman Produksi Media MAVIB (Multimedia Audio Visual and Broadcasting) Journal CCIT Vol.3 No.2.

[10] Rahinda, Yanu. 2013. Analisis dan Perancangan Video Iklan Pada Hotel Duta Garden Yogyakarta sebagai Media Promosi. STMIK AMIKOM Yogyakarta.

[11] Rahmawati, Indah. 2011. Menjadi Sutradara Televisi : Dengan Single Dan Multi Kamera, Jakarta : Grasindo.

[12] Wandanaya, Anita B. Dewi Immaniar Desrianti. Maryana Astuti. 2014. Design

Visualisasi Logo Sebagai Identity Programs Di Divisi Raharja Enrichment Centre. Journal CCIT Vol. 8 No. 1.

[13] Wahyu, E.P Sesar. 2013. Pembuatan Video Company Profile Berbasis Multimedia Pada Sekolah Menengah Pertama Negeri 4 Karanganyar. Universitas Surakarta [14] Wibowo, Fred. 2010. Teknik Produksi Program Televisi, Yogyakarta : Pinus 